\title{
Experimental Investigation on Propagation Behavior of Hydraulic Fractures in Coal Seam during Refracturing
}

\author{
Xun Sun $\mathbb{D}^{1},{ }^{1}$ Shicheng Zhang, ${ }^{1}$ Xinfang Ma, ${ }^{1}$ Yushi Zou $\mathbb{D},{ }^{1}$ and Guanyu Lin ${ }^{2}$ \\ ${ }^{1}$ China University of Petroleum, Beijing 102249, China \\ ${ }^{2}$ China National Offshore Oil Corporation, China \\ Correspondence should be addressed to Yushi Zou; zouyushi@126.com
}

Received 12 November 2018; Revised 23 January 2019; Accepted 24 February 2019; Published 2 May 2019

Academic Editor: Shengnan Nancy Chen

Copyright ( 2019 Xun Sun et al. This is an open access article distributed under the Creative Commons Attribution License, which permits unrestricted use, distribution, and reproduction in any medium, provided the original work is properly cited.

\begin{abstract}
Refracturing is an effective technology for reinstituting a percolation path and improving the fracture conductivity in coal measure strata. Hydraulic fracture (HF) propagation is complicated due to the presence of cleats and stress change caused by pore pressure changes. Many scholars have studied HF propagation in the initial fracturing of coal, but the refracturing in coal seams is rarely mentioned. In this study, laboratory refracturing experiments were conducted on large natural coal specimens under various triaxial stress states to investigate the propagation of HFs in coal seams. The mechanical properties of coal were tested before refracturing. The maximum and the minimum horizontal principal stresses are inverted to simulate the stress change caused by the production and pore pressure reduction of the stress condition after initial fracturing. Experimental results showed three different types of HF initiation and propagation during refracturing: (1) under low horizontal stress differences $(0-2 \mathrm{MPa}), \mathrm{HF}$ propagated along the cleats, and no new HFs were formed on the walls of the initial HFs regardless of changes in the horizontal stress; (2) under high horizontal stress differences (4-8 MPa) with no stress inversion, a major HF was initiated parallel to the orientation of maximum horizontal stress during initial fracturing; new branches propagated along cleats in the orientation of the minimum horizontal stress during refracturing; and (3) under high horizontal stress differences (4-8 MPa) with maximum and minimum horizontal stress inversions, the main HF formed along the orientation of the maximum horizontal stress, and a new HF perpendicular to the initial HF was formed during refracturing. Multiple factors affect fracture morphology during refracturing. Cleats affect the HF growth path and the creation of new branches. The in situ stress determines the initiation and propagation of new HFs.
\end{abstract}

\section{Introduction}

Coal seams are often characterized by extremely low permeability and a unique natural fracture network system consisting of cleats. Hydraulic fracturing is a widely applied measure that can create HFs and improve the connectivity of natural fractures (NFs) in coal seams [1-6]. However, during production, CBM wells tend to be deficient due to decreasing fracture conductivity, which results in declining productivity. Refracturing is an effective means to restore productivity after initial fracturing and after production is complete in unconventional reservoirs [7, 8]. Currently, the success rate of refracturing on underperforming fractured wells is not high, partially due to a lack of understanding of HF propagation. In addition, the anisotropy of coal, the existence of initial HFs, and the disturbance of earlier production activities all make refracturing treatments more complex. Further study on HF propagation in refracturing is required.

Low permeability leads to difficulty of gas flow inside the coal matrix, and cleats become the main channels to connect the matrix and the fractures [9-11]. Cleats are a unique fracture system consisting of face and butt cleats distributed in the interior of the coal seam. Face and butt cleats intersect bedding planes (BP) at a right or high angle, dividing the coal into a plurality of block matrices (Figure 1). The existence of this special structure determines the mechanical properties of the coal. Typically, compared to mudstone and sandstone, the Young modulus, shear modulus, and shear strength of coal are lower, the gradient of breakdown pressure is smaller, and the gradient of collapse pressure is larger $[12,13]$. 


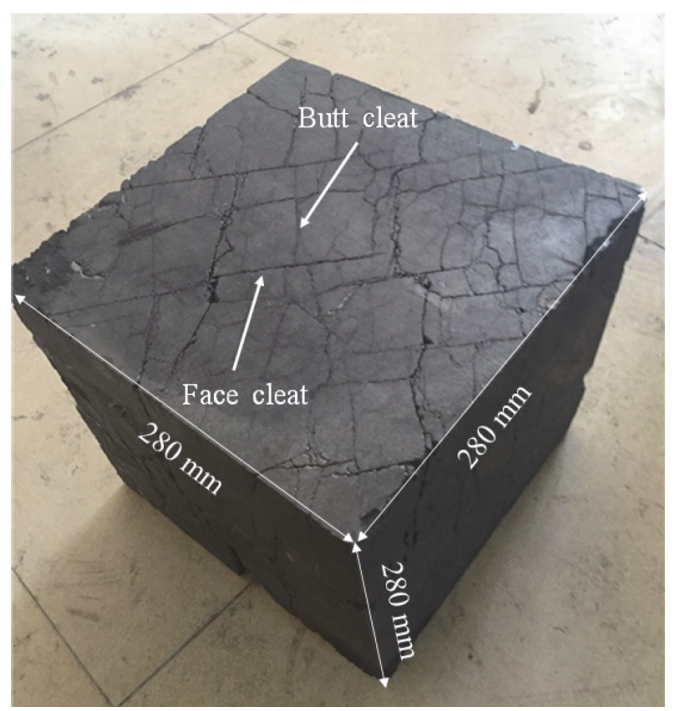

Figure 1: Cleat structure of coal at surface conditions.

Therefore, the fracture propagation mechanisms of a coal seam are likely to be distinct from those associated with conventional reservoirs. Many scholars have investigated hydraulic fracturing in coal seams using experiments [14-16] and numerical simulations [17-19]. They believe that a single horizontal or vertical fracture can be formed under a large principal stress difference during fracturing; they also observed that the blockage of the fracture entrance by pulverized coal may cause a great pressure drop in fractures near the wellbore. When the in situ stress variation occurs or a HF approaches cleats, HFs will change their growth orientation and propagate along cleats, break through at the weak point of a cleat, or be terminated at cleats. Many researchers have demonstrated that geological discontinuities represented by NFs, such as cleats, can effectively affect fracture propagation and morphology [20-22]. Some scholars [23] suggest that the fluid will first permeate the interface when HFs propagate along the vertical direction of a discontinuum. The research of Warpinski et al. [24] shows that NFs can cause a large amount of fluid filtration, create masses of branches, and make the main HF extend to the NF zone. Li et al. [25] studied the propagation mechanism of HFs in the coal seam roof and floor. Test results show that when the difference between vertical stress and horizontal stress is large ( $5 \mathrm{MPa})$, vertical HFs are formed during fracturing and HFs penetrate the roof and floor into the pay formation. The influence of NFs on HF propagation is related to the approaching angle, the parameters of the NFs, the injection pressure, and the in situ stress.

In addition to cleats, the distribution of the stress field also has an important influence on the expansion of HFs. A stress reversal region is formed because of the depletion of pore pressure [26]. The pore pressure is elliptically distributed around the initial HF after fracturing. During production, the distribution of pore pressure around fractures is depleted in an elliptical zone around the fracture, resulting in a larger stress reduction in the long direction of the ellipse; thus, the whole distribution of field stress changes when pore

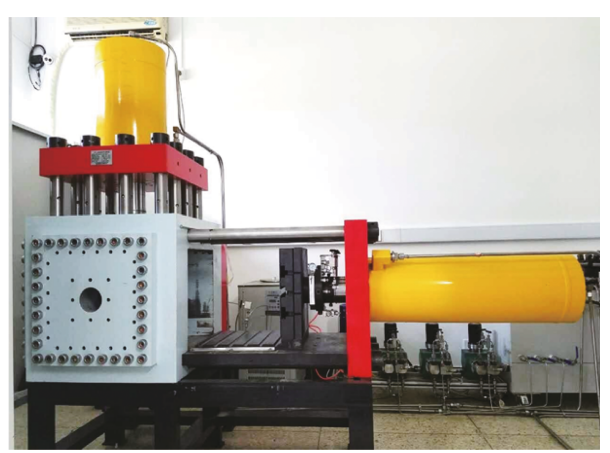

Figure 2: True triaxial hydraulic fracturing simulation test system (Ma et al., 2016).

pressure decreases [27]. Stress depletion along the direction of maximum horizontal stress is higher than that in the direction of the minimum horizontal stress. As a result, the stress reversal region forms in the vicinity of the initial HF [28]. Therefore, in the stress reversal region, new HFs may propagate along new orientations, a phenomenon reported from field tests [29] and laboratory experiments [30]. New HF propagation is affected by many factors, including stress states, mechanical properties of the rock, and initial HF parameters. Roussel and Sharma [31] consider the impact of the coupled poroelastic and mechanical effects on nearwellbore stress distribution. They conclude that the existence of an initial HF and changes of pore pressure induce fracture reorientation. Daneshy [32] considers the effect of fracturing fluid on the distribution of in situ stress near the fracture and demonstrates the possibility of changing the orientation of in situ stress.

Although many scholars have studied the HF propagation mechanism of coal during initial fracturing, refracturing in a coal seam has not been studied. In contrast to conventional reservoirs, changes in in situ stress and the existence of cleats lead to changes in the propagation mechanisms of HFs. Our understanding is constrained by the fact that few large coal specimens are used in hydraulic fracturing tests due to the difficulty of sampling and artificial rock samples cannot truly reflect the mechanical properties of coal. In this paper, we report on the propagation of HFs during true triaxial hydraulic fracturing simulation testing carried out with large natural coal samples from Qinshui Basin in Shanxi Province, China. The influences of cleats and stress inversion on the initiation and propagation of HFs during refracturing are studied. The test parameters $[33,34]$ are set up according to the scaling laws. Experimental results can explain the phenomenon that coal is different from the conventional reservoir during refracturing and provide theoretical basic support for refracturing in coal seams.

\section{Experimental Equipment and Procedure}

2.1. Experimental Equipment. We used a true triaxial hydraulic fracturing simulation test system (Figure 2) to conduct experiments on 10 cubical specimens measuring $300 \mathrm{~mm}$ to a side. The natural coals used in the experiment are taken from a typical outcrop of high-rank anthracite in the 
TABLE 1: Petrophysical properties of the testing coal.

\begin{tabular}{lc}
\hline Parameter & Value \\
\hline Porosity (\%) & 8.44 \\
Permeability $\left(10^{-3} \mathrm{mD}\right)$ & 1.91 \\
Poisson's ratio perpendicular to BP & 0.417 \\
Poisson's ratio parallel to BP & 0.407 \\
Young's modulus perpendicular to BP $(\mathrm{GPa})$ & 6.03 \\
Young's modulus parallel to BP $(\mathrm{GPa})$ & 5.65 \\
Tensile strength perpendicular to BP $(\mathrm{MPa})$ & 2.71 \\
Tensile strength parallel to BP $(\mathrm{MPa})$ & 2.34 \\
Compressive strength perpendicular to BP $(\mathrm{MPa})$ & 93.78 \\
Compressive strength parallel to BP $(\mathrm{MPa})$ & 79.98 \\
\hline
\end{tabular}

southern part of Qinshui Basin, Shanxi Province, China. Before the refracturing experiments, mechanical properties were measured via triaxial compression and Brazilian tests. The high-rank anthracite has an ultralow porosity of $8.44 \%$ and a permeability of $1.91 \times 10^{-3} \mathrm{mD}$, respectively. The coal specimens are anisotropic due to the presence of cleats with multiple directionalities. They exhibit distinctly different mechanical properties measured parallel and perpendicular to bedding planes (BPs). The petrophysical properties of the testing coal are shown in Table 1.

During sample preparation, a borehole with a diameter of $16 \mathrm{~mm}$ and a length of $165 \mathrm{~mm}$ was drilled along the vertical direction. Then, a steel tube with an outer diameter of $15 \mathrm{~mm}$, an inner diameter of $8 \mathrm{~mm}$, and a length of $135 \mathrm{~mm}$ was bonded to the center hole of the specimen by epoxy resin, forming a simulated wellbore. An open-hole section of $30 \mathrm{~mm}$ was left in the lower part as a HF initiation point. The complete process of specimen preparation is shown in Figure 3. In order to study the influence of cleats on the HF propagation, we chose the specimens with multiple cleats at the top of the surface. Figure 4 shows the internal structure of a typical specimen.

In order to consider the similarity between the physical phenomena observed in the field and the results of the experimental model, the scaling laws are applied to improve the credibility of the experiment itself $[35,36]$. Parameters of this test are shown in Table 2, where $\sigma_{\mathrm{v}}$ is the vertical stress of the formation, $\sigma_{\mathrm{H}}$ is the maximum horizontal principal stress, $\sigma_{\mathrm{h}}$ is the minimum horizontal principal stress, $\sigma_{\mathrm{H}}^{\prime}$ is the maximum horizontal principal stress after stress inversion, and $\sigma_{\mathrm{h}}^{\prime}$ is the minimum horizontal principal stress after stress inversion. A constant injection rate $(20 \mathrm{~mL} / \mathrm{min})$ is selected for fracturing, and the fracturing fluid is active water $(\mu=0.001 \mathrm{Pas})$. The main components of active water are clear water, surfactant, antiswelling agent, and cleanup agent. Active water has the characteristics of low viscosity, low damage to coal seams, and easy to flow back, and it is widely used in coal seam fracturing. The green fluorescent agent, which can adhere to the surface of fractures and has no negative effect on the rheological properties of active water, is added to the initial fracturing fluid, whereas the blue fluorescent agent is added to the refracturing fluid, allowing us to distinguish HFs generated by different processes.
2.2. Experimental Procedure. To compact the bedding plane and prevent shear failure in specimens before experiments, the orientations of $\sigma_{\mathrm{v}}, \sigma_{\mathrm{H}}$, and $\sigma_{\mathrm{h}}$ were applied sequentially. $\sigma_{\mathrm{v}}$ was first applied in the $x$-axis direction; then, $\sigma_{\mathrm{H}}$ and $\sigma_{\mathrm{h}}$ were applied in the $y$-axis and $z$-axis directions. After stress loading, specimens stood for $30 \mathrm{~min}$ in order to balance stress around the wellbore [37]. Table 2 lists the experimental scheme and design parameters. During the experiments, the injection pressure at the wellhead was monitored. HFs connected cleats continually during the fracturing process due to the heterogeneity of coal; under the action of pump pressure and liquid filtration, cleats near the HFs were opened and closed repeatedly, resulting in frequent pressure curve fluctuations [38]. After initial fracturing, the maximum and the minimum horizontal principal stresses were inverted. Then, the initial fracturing steps were duplicated. The syringe pump was kept under shut-in until the injection pressure remained stable at a low level. Finally, the specimen was taken from the loading frame and split to reveal the morphology of the initial and new HFs.

\section{Experimental Results and Analysis}

Experiment results are shown in Table 3. After the experiment, the fractured specimens were split along the surface, allowing us to observe the morphologies of the HF. Since results under the same conditions show similar test phenomena, only six representative test results $(1,2,4,5,7$, and 9) are shown here. In general, HFs initiate as horizontal fractures in shallow conventional reservoirs and as vertical fractures in the deep conventional reservoir. However, our results show that fracture propagation is extremely complex in a coal seam; fracture morphologies were characterized as stairstep, tortuous, and asymmetrical. Figures 5(a), A, B, 5(b), A, B, $5(\mathrm{c}), \mathrm{A}, \mathrm{B}, 5(\mathrm{~d}), \mathrm{A}, \mathrm{B}$, and 5(e), A, B present the fracture geometry of each specimen after refracturing; Figures 5(a), C, 5(b), C, 5(c), C 5(d), C, 5(e), C, and 5(f), C present the internal structure of each specimen after refracturing. Fractures formed during initial fracturing are represented by red dashed lines, and fractures formed during refracturing are represented by yellow dashed lines.

3.1. Injection Pressure Curves. Figure 6 shows the curves of injection pressure versus time for the refracturing experiments. Injection pressure increased rapidly from zero when active water flowed into the wellbore until it reached a peak value. Afterward, it decreased sharply, indicating that HFs were formed in the open-hole section. Then, active water flowed into HFs and cleats. During the injection process, HFs connected cleats continuously at an extension pressure, and cleats near the main HF were frequently opened and closed under the action of the pump pressure and liquid filtration, thereby causing pressure curve fluctuation until the pump was shut in. The pressure curve patterns under different experimental conditions were distinctly different, especially in terms of breakdown pressure. Specimens without new HFs during refracturing (1, 2, 5, and 9) had a higher breakdown pressure for initial fracturing than for refracturing (Figures 6(a), 6(b), 6(d), and 6(f)). 


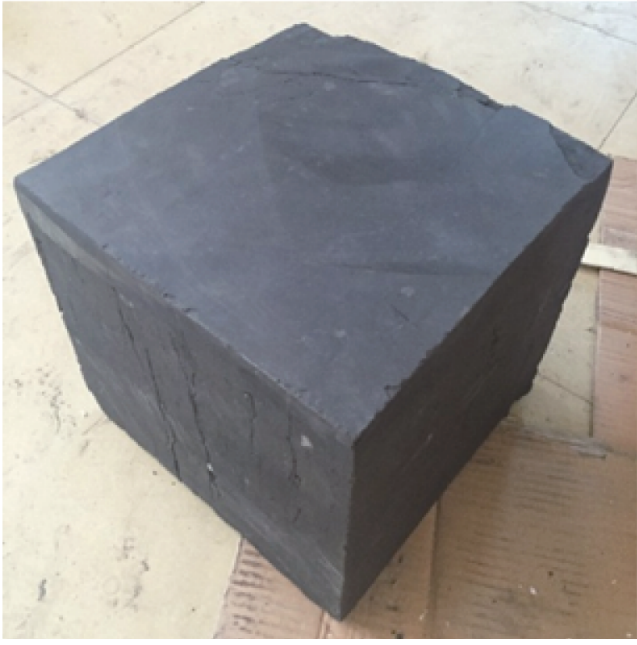

(a)

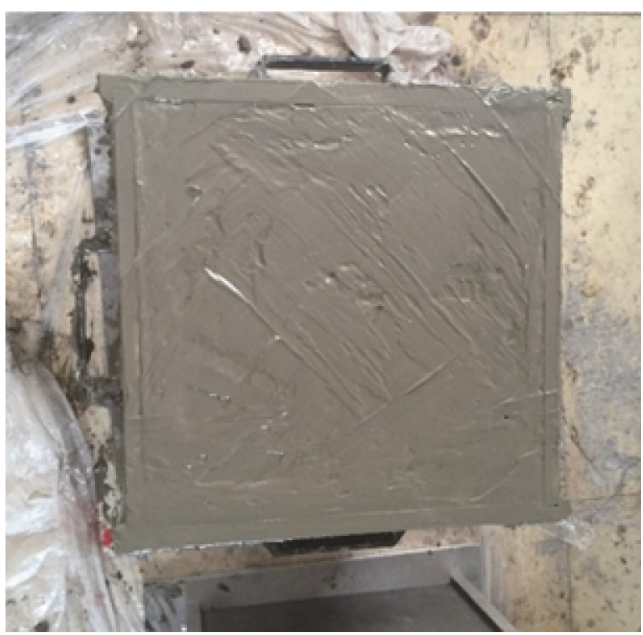

(c)

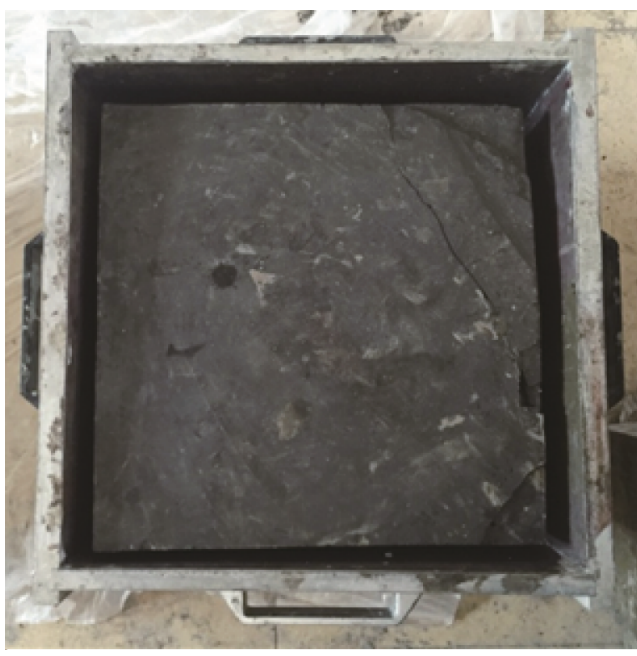

(b)

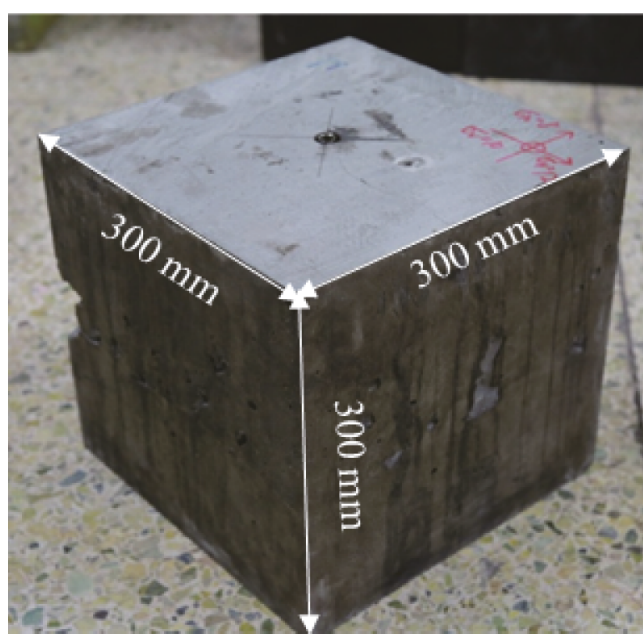

(d)

Figure 3: Preparation of standard specimen: (a) cut coal into a cube; (b) load coal sample into the mould; (c) pour cement; (d) complete standard specimen.

No obvious breakdown pressure could be observed in the curve of specimen 9 (Figure 6(f)). The observation of this specimen showed that cleats and NFs were widely distributed on the specimen surface. During the drilling process, due to the external stress, fractures were initiated near the open hole and wellbore when the borehole intersected with cleats. Active water directly flowed into these fractures and cleats during fracturing. Thus, pressure could not be built effectively in the open-hole section, resulting in no obvious breakdown pressure drop.

Remarkably, for specimens with new HFs during refracturing, the breakdown pressure of initial fracturing was equal in value (specimen 7) (Figure 6(e)) or lower than that of refracturing (specimen 4) (Figure 6(c)). After initial fracturing, fluid pressure inside the fractures were reduced, and additional stress existed in two orientations: perpendicular to the fracture and parallel to the fracture. During the refracturing process, fracture reorientation occurred only when the net pressure exceeded the sum of the horizontal stress difference and the rock tensile strength [39-42]. As fractures always propagated along the minimum resistance zone [43], if the net pressure failed to meet the minimum requirement, fractures preferentially extended along the initial fracture and cleats, resulting in a breakdown pressure of refracturing that was lower than the initial breakdown pressure. The formation of new HFs is also influenced by the comprehensive effects of cleats and the in situ stress field. This will be discussed in the subsequent sections.

3.2. Cleat Influence on HF Geometry. Figure 5(a), showed that the initial HF in specimen 1 did not propagate entirely along the orientation of $\sigma_{\mathrm{H}}$ but instead deflected about 45 degrees from the horizontal direction. HFs deflected when they encountered face cleats, propagating along them to form the major HF. Butt cleats were connected to the major HF subsequently when more fluid was injected into the wellbore, resulting in a rough, zigzagging propagation path. HFs on the specimen surface did not intersect with the wellbore; this result was also found in coal mines [44]. A similar phenomenon was observed in specimen 2 . In this case, fracture 


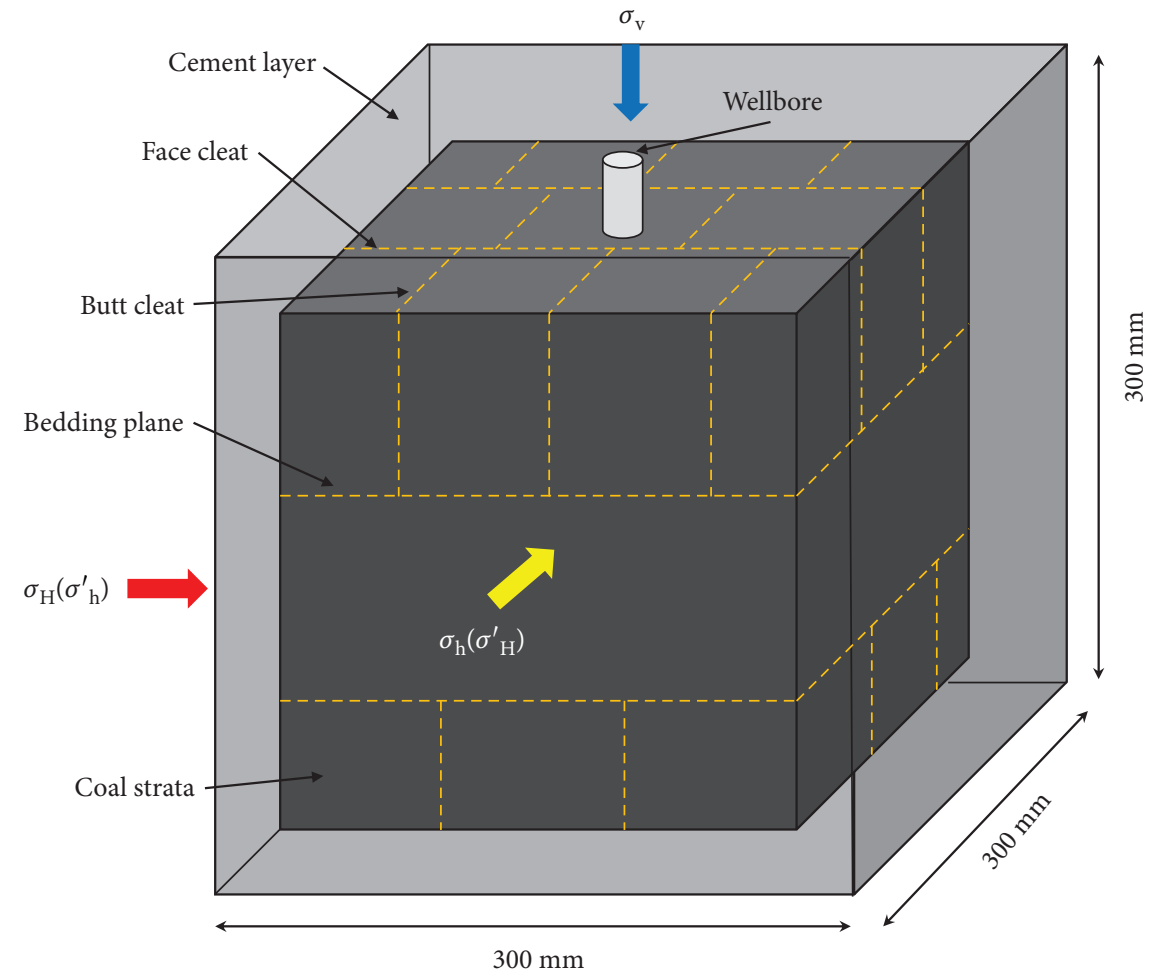

FIGURE 4: Internal structure of specimen.

TABle 2: Parameters used during refracturing simulation experiments in coal.

\begin{tabular}{lcccc}
\hline Specimen number & $\begin{array}{c}\text { In situ stress (initial fracturing) } \\
\sigma_{\mathrm{v}}, \sigma_{\mathrm{H}}, \sigma_{\mathrm{h}}(\mathrm{MPa})\end{array}$ & $\begin{array}{c}\text { In situ stress (refracturing) } \\
\sigma_{\mathrm{v}}, \sigma_{\mathrm{H}}^{\prime}, \sigma_{\mathrm{h}}^{\prime}(\mathrm{MPa})\end{array}$ & $\begin{array}{c}\text { Injection rate }(\mathrm{mL} / \mathrm{min}) \\
\text { Fluid viscosity }(\mathrm{mPa} \cdot \mathrm{s})\end{array}$ \\
\hline 1 & $15,12,10$ & $15,10,12$ & 20 & 1 \\
2 & $15,12,10$ & $15,12,10$ & 30 & 1 \\
3 & $15,12,10$ & $15,12,10$ & 20 & 1 \\
4 & $15,12,8$ & $15,8,12$ & 20 & 1 \\
5 & $15,12,8$ & $15,12,8$ & 30 & 1 \\
6 & $15,12,8$ & $15,12,8$ & 20 & 1 \\
7 & $15,12,6$ & $15,6,12$ & 20 & 1 \\
9 & $15,12,6$ & $15,12,6$ & 20 & 1 \\
10 & $15,12,4$ & $15,4,12$ & 20 & 1 \\
\hline
\end{tabular}

initiation was along $\sigma_{\mathrm{h}}$ near the wellbore and intersected with a face cleat after propagating upward approximately $2.5 \mathrm{~cm}$ (Figure 5(b)).

Our results show that the unique natural fracture system of each sample has a crucial impact on HF growth during fracturing. Developments of microfractures are higher in coal seams than in conventional reservoir rocks. These microfractures, represented by cleats, are in closure status under initial stress conditions. Cleats tend to be activated preferentially due to the low friction coefficient when the fracture fluid is injected $[45,46]$, and the stress state and stress intensity factor on the fracture tip will be changed as a result. Laboratory tests and theoretical deductions show that the stress field, especially the direction of stress, changes appreciably when HFs intersect with preexisting discontinuities, resulting in a tensile stress concentration area between fracture tips. When tensile stress overcomes fracture toughness at the tips of cleats, HFs will propagate along cleats and enhance the connectivity between HFs and NFs.

3.3. Influences of Geostress on HF Geometry. Two aspects of the influences of geostress on HF propagation in coal during refracturing were investigated: (1) the horizontal stress difference $\left(\Delta \sigma_{\mathrm{h}}=\sigma_{\mathrm{H}}-\sigma_{\mathrm{h}}\right)$ and (2) the inversion of in situ stress. 
TABLE 3: Experimental parameters and results of refracturing in coal.

\begin{tabular}{|c|c|c|c|c|}
\hline \multirow{2}{*}{$\begin{array}{l}\text { Specimen } \\
\text { number }\end{array}$} & \multirow{2}{*}{$\begin{array}{c}\sigma_{\mathrm{H}}-\sigma_{\mathrm{h}} \\
(\mathrm{MPa})\end{array}$} & \multicolumn{2}{|c|}{$\begin{array}{c}\text { Breakdown pressure } \\
(\mathrm{MPa})\end{array}$} & \multirow[t]{2}{*}{ Fracture geometry } \\
\hline & & Initial fracturing & Refracturing & \\
\hline 1 & 2 & 9.28 & 4.54 & Initial HF connected with cleats, no new HFs were formed \\
\hline 2 & 2 & 4.14 & 2.97 & Initial HF was initiated from cleats, no new HFs were formed \\
\hline 3 & 2 & 5.23 & 3.15 & An initial HF connected with cleats and BPs, no new HFs were formed \\
\hline 4 & 4 & 8.86 & 11.30 & A new HF was perpendicular to the initial HF \\
\hline 5 & 4 & 23.03 & 16.40 & New branches propagated along cleats \\
\hline 6 & 4 & 8.47 & 5.36 & New HFs connected with cleats \\
\hline 7 & 6 & 15.02 & 13.65 & New HFs were perpendicular to the initial HF \\
\hline 8 & 6 & 12.68 & 7.34 & A simple initial HF connected with cleats, no new HFs were formed \\
\hline 9 & 8 & 4.46 & 1.82 & A HF network consisting of initial HFs and cleats, no new HFs were formed \\
\hline 10 & 8 & 13.58 & 8.74 & A initial HF connected with cleats and two BPs, no new HFs were formed \\
\hline
\end{tabular}

3.3.1. Horizontal Stress Difference. Specimens 1 and 2 were both under a low horizontal stress difference $\left(\Delta \sigma_{\mathrm{h}}=2 \mathrm{MPa}\right)$. Due to the strong heterogeneity of coal, HFs were initiated in the open-hole section and propagated randomly along the cleats (Figures 5(a) and 5(b)). With increasing values of $\Delta \sigma_{\mathrm{h}}(4-8 \mathrm{MPa})$, the HFs tended to increasingly penetrate through cleats and propagate along the orientation of $\sigma_{\mathrm{H}}$. During refracturing, some new HFs were initiated near the major HFs, which opened multiple cleats. This observation can be explained by the fact that cleats are more permeable when subject to low horizontal stress differences, which, in coal, tend to occur at high permeability pathways and weak cemented planes. HFs will propagate preferentially along cleats. In contrast, large horizontal stress differences exert more pressure on the cleats, and HFs will propagate in the orientation of $\sigma_{\mathrm{H}}$ under the effect of higher horizontal stress differences. However, a fracture network composed of HFs intersected with cleats and beddings was found in specimen 9 , which was under a large horizontal stress difference $\left(\Delta \sigma_{\mathrm{h}}=8 \mathrm{MPa}\right)$ (Figure $\left.5(\mathrm{f})\right)$. The observation of this split specimen showed that numerous NFs and beddings developed around the wellbore, which weakened the strength of coal. Most of the fractures marked with red dashed lines indicate that refracturing led to a dilation of these preexisting NFs rather than the creation of new HFs.

Although it is difficult to create a fracture network because of the high $\Delta \sigma_{\mathrm{h}}[33,38]$, our results indicate that during refracturing, using active water can be conducive to the increase in the complexity of HFs in coal seams. A similar phenomenon was observed in shale by using low viscosity fluids [47].

3.3.2. The Inversion of In Situ Stress. The inversion of in situ stress also greatly influences the creation of new HFs. Some research has shown that the distribution of the stress field would be changed by the existence of initial HFs and production activities; hence, the direction of a new HF propagation can be reoriented [27, 29, 48, 49]. A similar phenomenon was found in specimens 4 and 7 (Figures 5(c) and 5(e)). With the vertical stress $\left(\sigma_{\mathrm{v}}=15 \mathrm{MPa}\right)$ and horizontal stress differences
$\left(\Delta \sigma_{\mathrm{h}}=4 \mathrm{MPa}\right)$ after stress inversion, a single-wing $\mathrm{HF}$ was created in specimen 4. This HF propagated upward orthogonal to the initial HF. The new HF encountered cleats and NFs constantly on the growth path (Figure 5(c)). Specimen 7 experienced a higher horizontal stress difference $\left(\Delta \sigma_{\mathrm{h}}=6 \mathrm{MPa}\right)$. In this case, new HFs were also observed, but unlike specimen 4, the new HFs extended upward and downward simultaneously in the vertical direction of the initial HF, indicating the generation of more complex fractures (Figure 5(e)). Figure 5(d) shows a different HF morphology without stress variation in specimen $5\left(\Delta \sigma_{\mathrm{h}}=4 \mathrm{MPa}\right)$. Only two branches were formed during fracturing, which were distributed symmetrically with the wellbore at the center. Experimental observations suggest that it is difficult to create new HFs in refracturing if the horizontal stress difference is less than $4 \mathrm{MPa}$ (Figure 5(b)), even with the stress inversion (Figure 5(a)). However, this also depends on the viscosity and injection rate of the fluid and the conductivity of the existing fracture and cleat system. Specimen 9 was under the highest horizontal stress difference $\left(\Delta \sigma_{\mathrm{h}}=8 \mathrm{MPa}\right)$; with the inversion of the two horizontal stresses, the original fractures were reopened and HFs propagated along the old orientation (Figure 5(f)) due to the massive development of cleats and NFs inside the coal. The experimental results show that reorientation does not always occur in naturally fractured rocks. When the stress change induced by production is weak, the existence of an initial hydraulic fracture may provide a low-energy pathway for the refracture growth, which makes it difficult to create new fractures during refracturing.

A critical indicator of a successful refracturing is the presence of new HFs. As shown in Figure 5, the geometries of HFs after refracturing are complex. By combining our knowledge of experimental conditions with the magnitude of $\Delta \sigma_{\mathrm{h}}$ and inversion of $\sigma_{\mathrm{H}}$ and $\sigma_{\mathrm{h}}$, we can find that the stress condition of the reservoir has a great influence on fracture propagation. In the refracturing treatment, $\mathrm{HFs}$ tend to propagate along initial HFs and NFs under low $\Delta \sigma_{\mathrm{h}}$ conditions no matter how stress changes; by contrast, under large $\Delta \sigma_{\mathrm{h}}$, HFs initiate at weak points on the surface of the initial HFs and propagate 


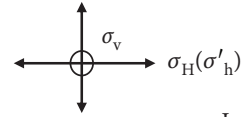

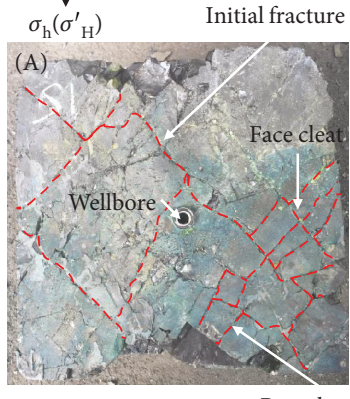

- - Initial fracture New fracture

Initial fracture

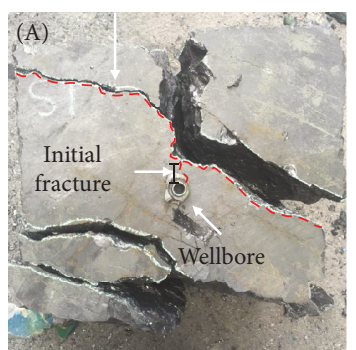

- - Initial fracture

New fracture

New fracture

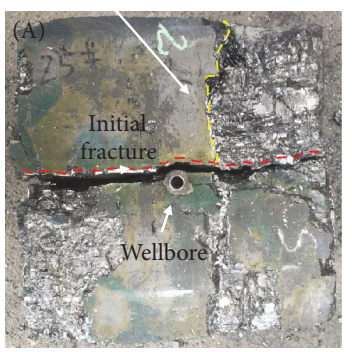

- - Initial fracture

New fracture

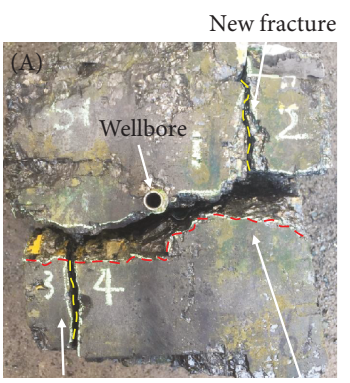

New fracture

- - Initial fracture

$$
\text { - New fracture }
$$
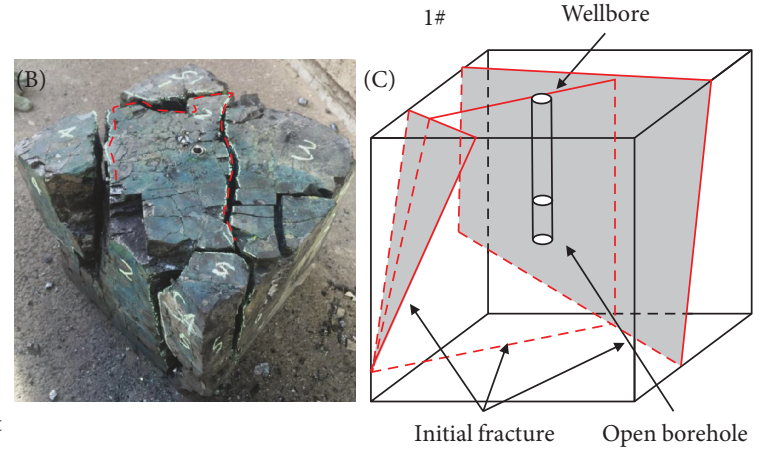

(a)

Wellbore

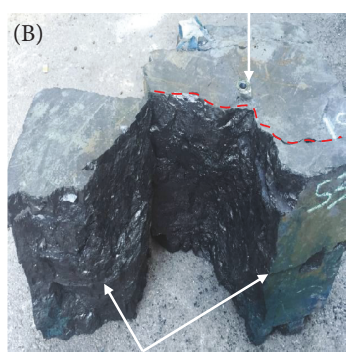

Bedding

(b)
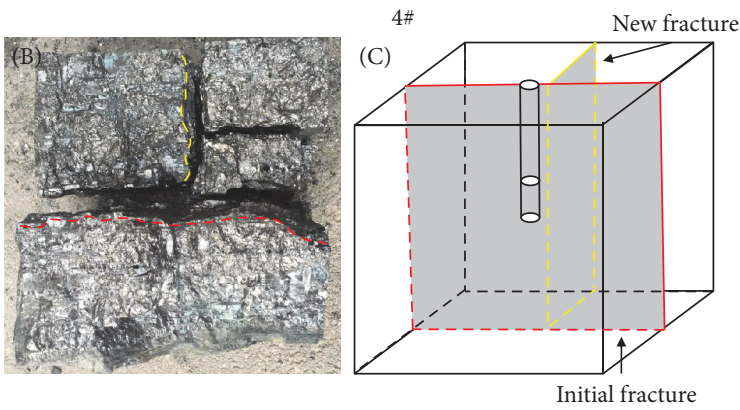

(c)

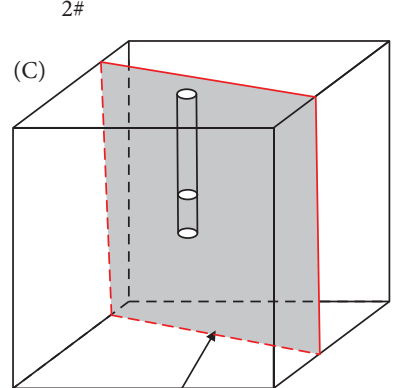

Initial fracture
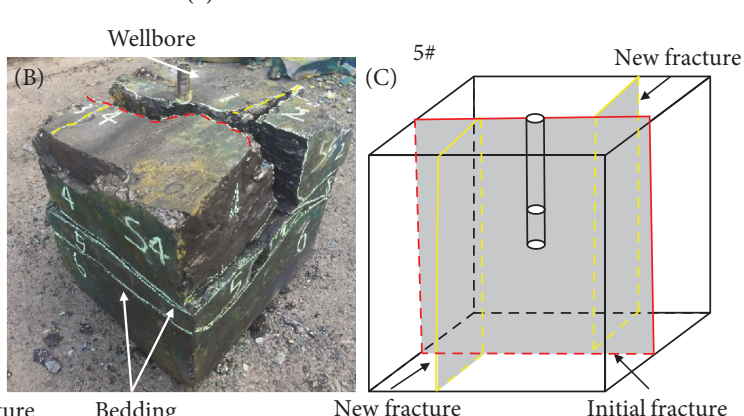

New fracture

Initial fracture

Bedding

(d)

Figure 5: Continued. 

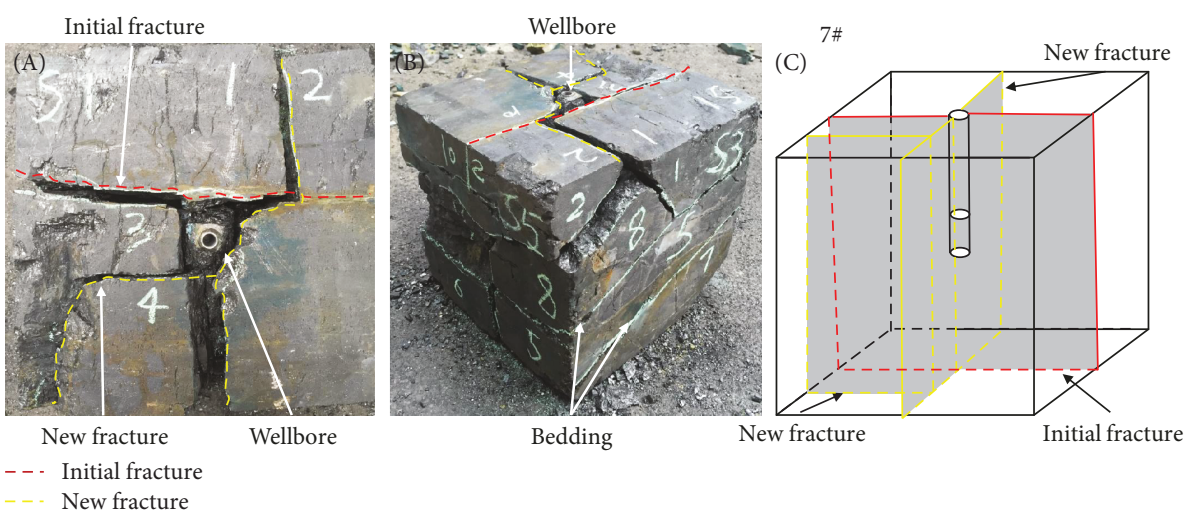

(e)
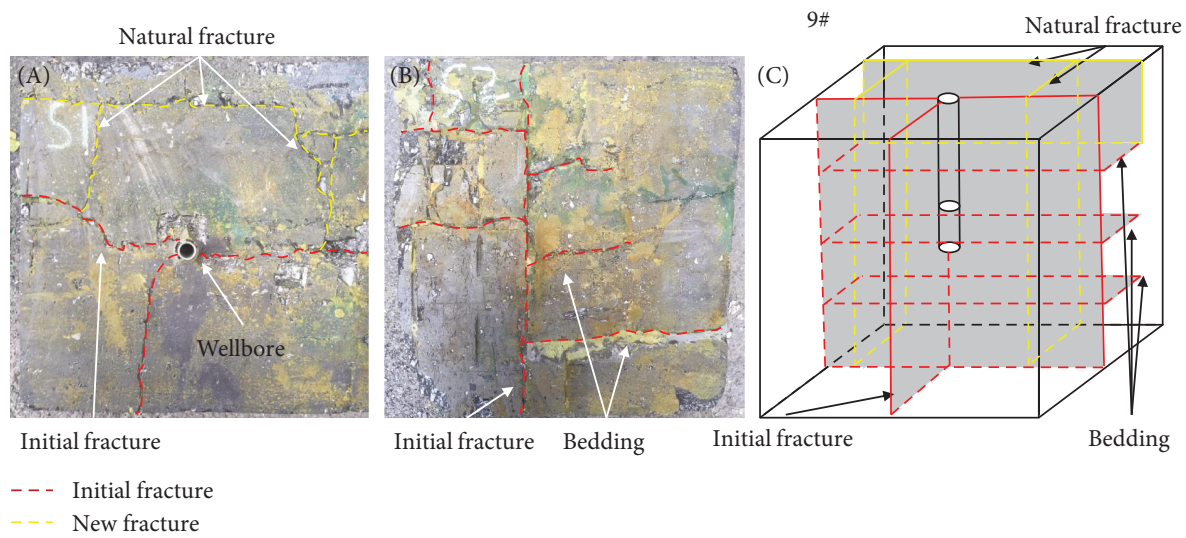

(f)

FiguRE 5: Experimental results of fracture geometry after refracturing.

along the $\sigma_{\mathrm{h}}$ direction without stress inversion. Only under large $\Delta \sigma_{\mathrm{h}}$ and with stress inversion are new HFs formed and propagate perpendicular to initial HFs. According to the experimental results, HF initiation and propagation in coal during refracturing are divided into three types:

(1) Type $1 \Delta \sigma_{\mathrm{h}}$ was small $(0-2 \mathrm{MPa})$. The initial HF was initiated and propagated along cleats. No new HFs were formed during refracturing with or without stress inversion (Figure 7(a)), such as in specimens 1 and 2. Many cleats developed around the wellbore of the specimen. Fracturing fluid leaked quickly after entering the wellbore, leading to the low pressure in the wellbore and the generation of no new HFs. The fracturing fluid could only open the nearby cleats and interconnect with the internal pores and fractures.

(2) Type $2 \Delta \sigma_{\mathrm{h}}$ was large (4-8 MPa). The initial HF was initiated in the coal matrix and propagated along the orientation of $\sigma_{\mathrm{H}}$. The stress field was not changed much during refracturing, and new branches (Figure 7(b)) were formed perpendicular to the initial HF. Specimen 5 belongs to this type. The ability of stress to control fractures was enhanced, and the pressure inside the fractures increased with the gradual injection of fracturing fluid. When the pressure exceeded the breakdown pressure of weak points on the initial HF surface, such as cleats, a new branch continued to propagate along the cleat, ultimately forming a complex fracture system composed of HFs and NFs.

(3) Type $3 \Delta \sigma_{\mathrm{h}}$ was large (4-8 MPa). The initial HF propagated along the maximum horizontal stress orientation. When the inversion of $\sigma_{\mathrm{H}}$ and $\sigma_{\mathrm{h}}$ occurred during refracturing, new HFs propagated along the vertical direction of the initial HF (Figure 7(c)). Specimens 4 and 7 belong to this type. Fracture orientations of this type fully propagated along an orientation perpendicular to $\sigma_{\mathrm{h}}$, and cleat development was further from the wellbore. Fracture initiation and propagation occurred inside the coal matrix; at the same time, energy could be saved effectively with continuous injection of fluid. As the net pressure reached the minimum requirements of fracture inversion, new HFs were ultimately initiated along the orientation of $\sigma_{\mathrm{H}}^{\prime}$.

\section{Discussion}

Of the three types of refracture initiation and propagation summarized above, Type 3 is the best for CBM refracturing engineering. Less intensive coal cleat development can 


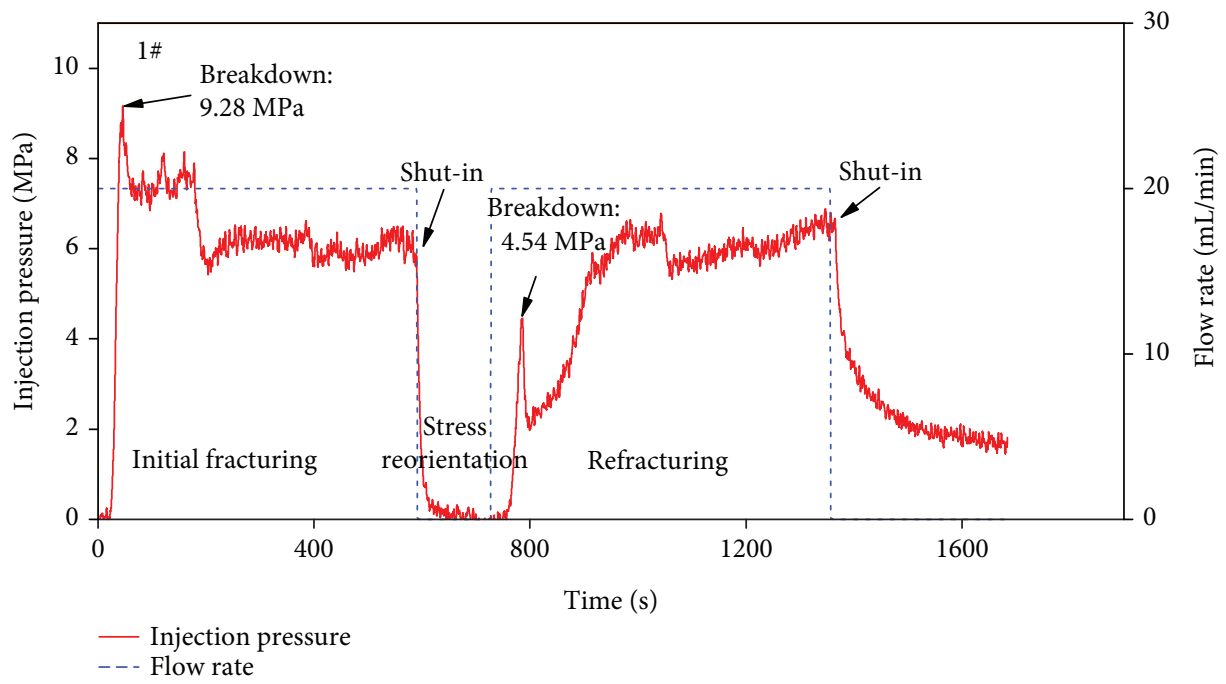

(a)

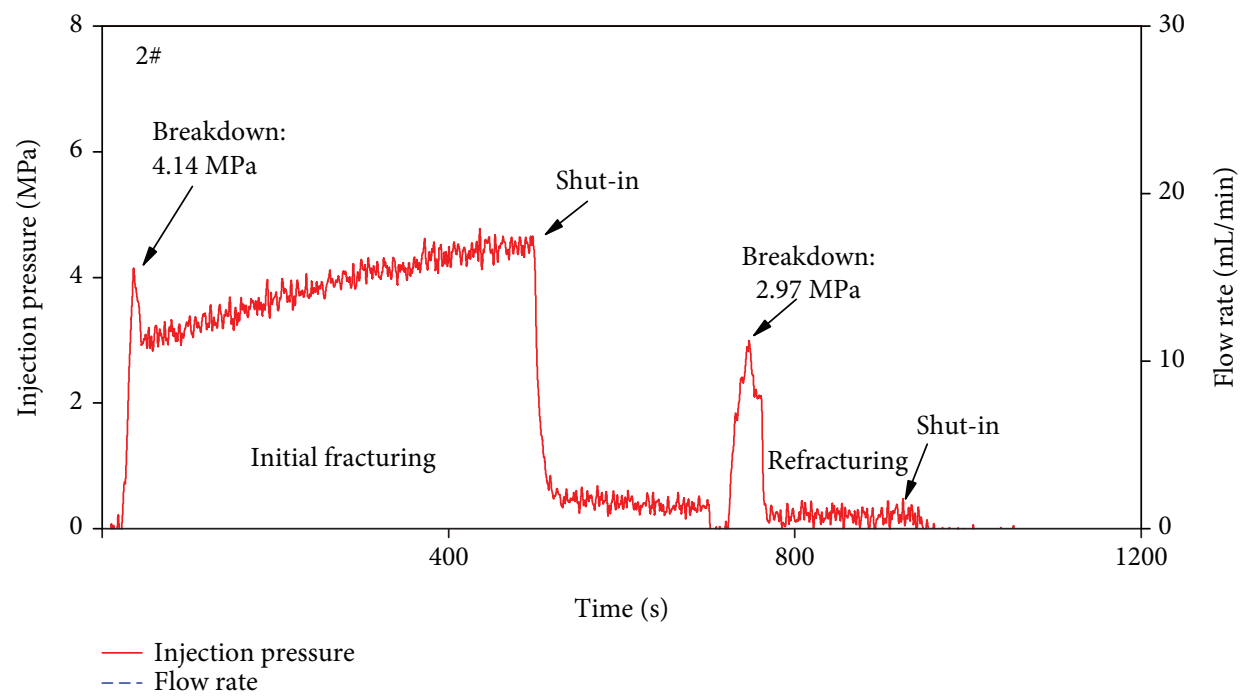

(b)

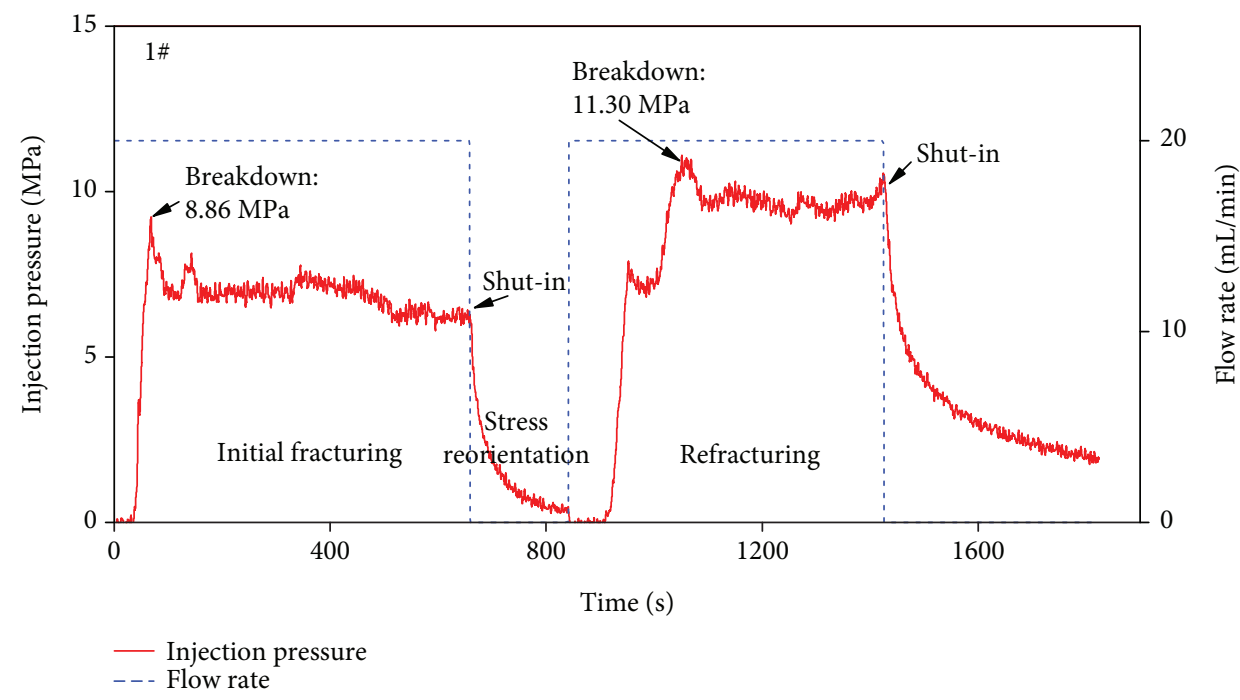

(c)

Figure 6: Continued. 


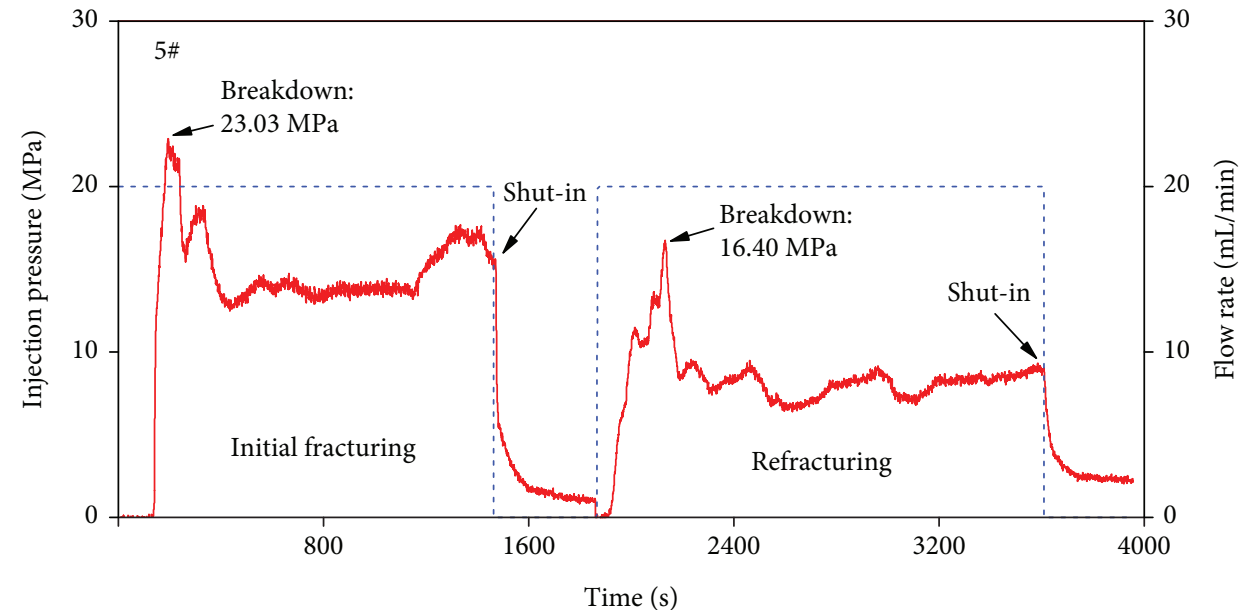

- Injection pressure - - Flow rate

(d)

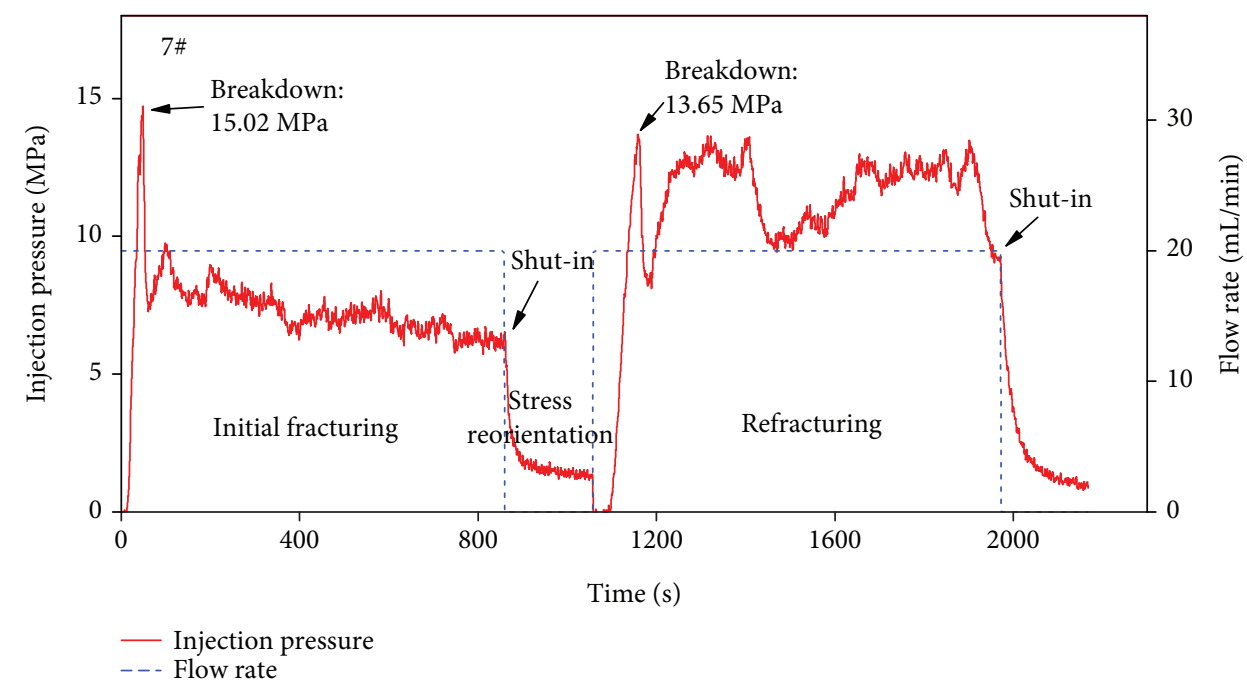

(e)

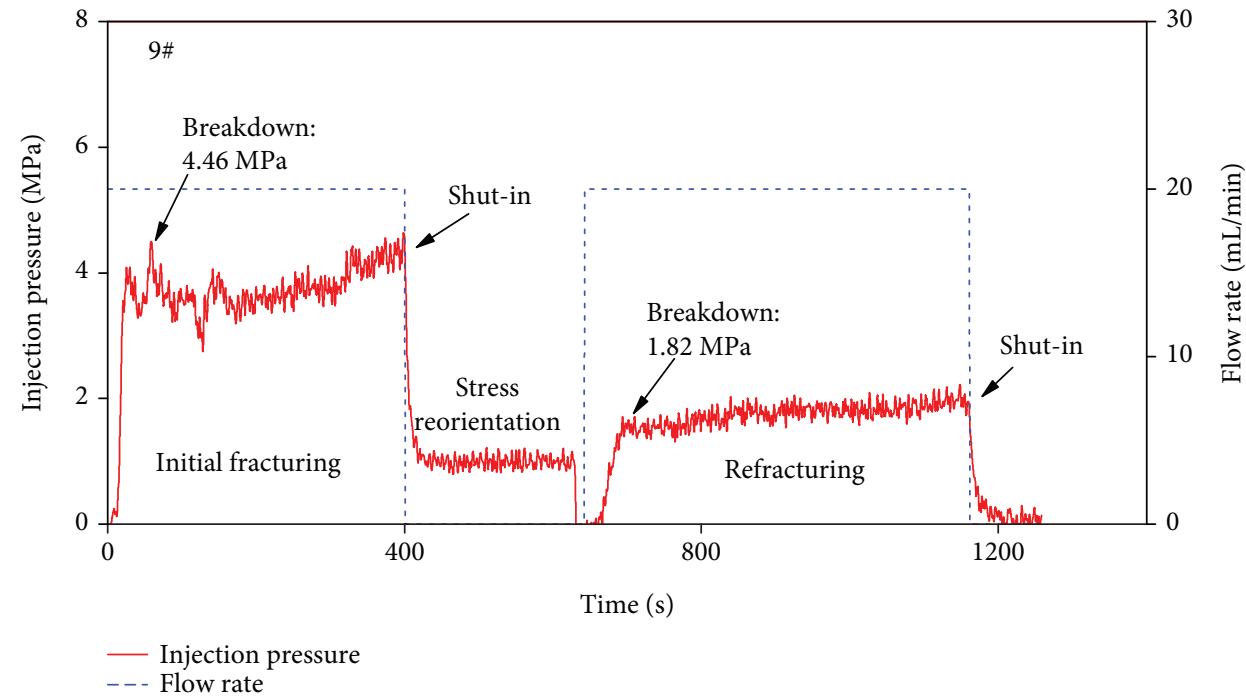

(f)

FIGURE 6: Injection pressure curves for refracturing experiments. 


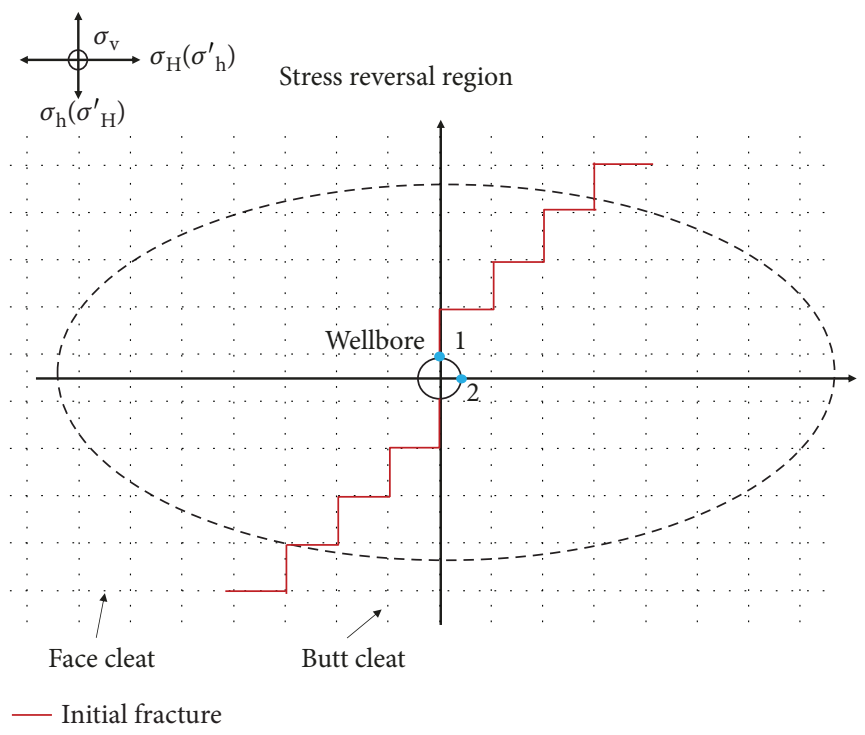

(a)

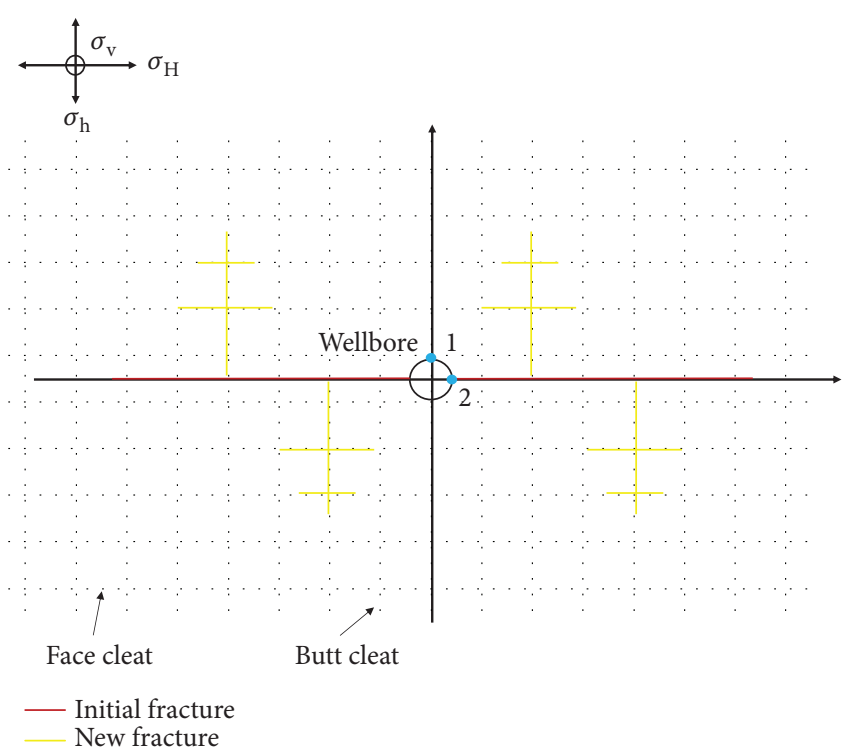

(b)

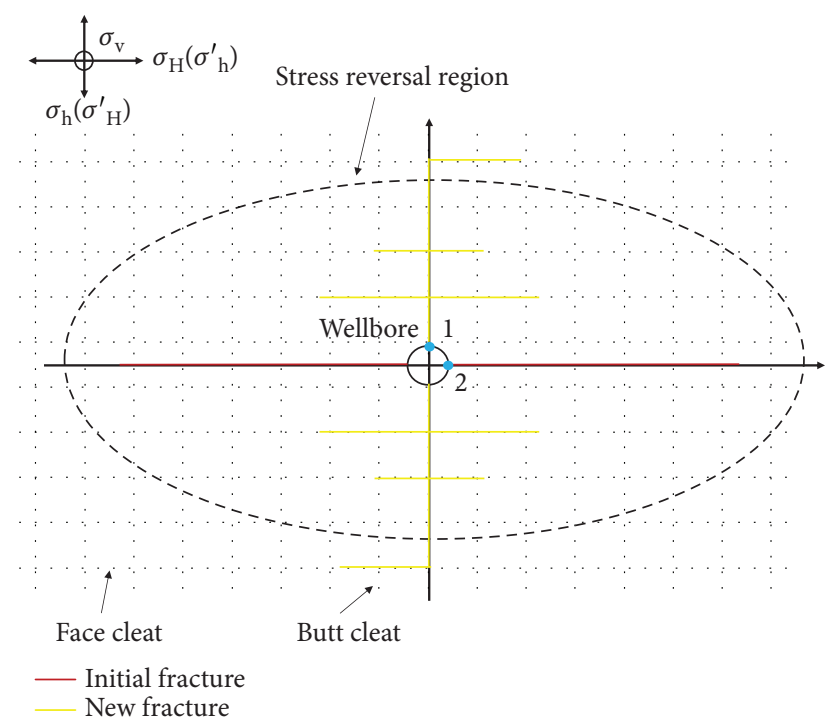

(c)

FIGURE 7: Fracture morphologies under different conditions in coal seams in refracturing: (a) $\Delta \sigma_{\mathrm{h}}$ was small ( $\left.0-2 \mathrm{MPa}\right)$, and no new HFs were formed; (b) $\Delta \sigma_{\mathrm{h}}$ was large (4-8 MPa), and the stress field was not changed much and new branches were formed perpendicular to the initial HF; and (c) $\Delta \sigma_{\mathrm{h}}$ was large (4-8 MPa), with stress inversion, and new HFs were created in refracturing.

reduce the filtration of fracturing fluids, expand the coverage area of the fractures, and improve coalbed methane exploitation. Meanwhile, HFs in new orientations communicate with cleats during refracturing, employing the area untouched in the initial fracturing treatment effectively and improving productivity greatly. For wells that may not be in the optimal refracturing timing, some techniques can be taken to generate new diverting HFs. These include temporary plugging of initial HFs or perforations and diverting fracturing elsewhere, thus increasing the contact area with the coal seam.

Various factors affect the generation of new HFs, key among them is the distribution of the stress field. The chance to create new HFs in the stress reversal region is more obvious. Meanwhile, larger horizontal stress differences prevent initial HFs from reopening. A smaller tensile strength helps new HFs to initiate on the surface of initial HFs, which is a favorable factor for coal. Our research proves that refracturing is a promising way to increase productivity and achieve significant economic benefits in coal seam hydraulic fracturing.

The type of fracturing curve and the magnitude of breakdown pressure closely correlate with the propagation process of hydraulic fractures in coal seams. The initiation position (inside the cleat and matrix) can be determined by comparing breakdown pressures. As shown in Figure 8, in this experiment, if the fracture was initiated in cleats, the first breakdown pressure varied between 4.14 and 9.28 $\mathrm{MPa}$, and the second breakdown pressure varied between 1.82 and 


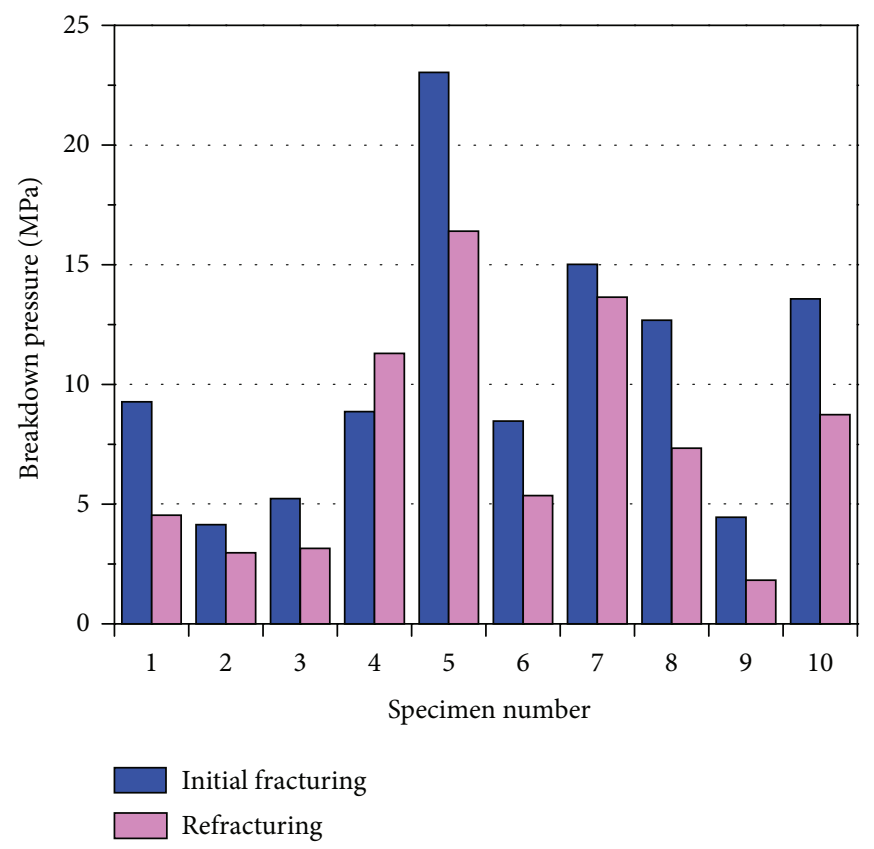

FIgURE 8: Comparison of breakdown pressure between two phases.

4.54 $\mathrm{MPa}$ (specimens 1, 2, 3, and 9). If the fracture was initiated in the matrix of the coal, the first breakdown pressure varied between 8.47 and $23.03 \mathrm{MPa}$, and the second breakdown pressure varied between 5.36 and $16.40 \mathrm{MPa}$ (specimens 4, 5, 6, 7, 8, and 10), higher than the breakdown pressure for the cleats. The form of new HFs of refracturing can be judged by comparing breakdown pressures of the initial fracturing and refracturing. The second breakdown pressure is obviously lower than the first breakdown pressure, which indicates that the initial HF is reopened or further extended during refracturing (specimens 1, 2, 5, and 9). If the second breakdown pressure is higher or close to the first breakdown pressure, a new HF may be generated (specimens 4 and 7). As coal is relatively heterogeneous within and among specimens, breakdown pressures vary sharply. The breakdown pressure probably is not included in the given range, but the analysis of the fracturing curve can be used as a kind of speculation of HFs.

Comparing the results in our experiments with the mineback observation from Diamond and Oyler [44], we can find that fracture geometries are similar. Multiple fractures were distributed around the wellbore, and the complexity of fractures decreased as the distance from borehole increased. Most of the fractures propagated along face cleats or penetrated face cleats and butt cleats occasionally. The fracture growth path depended on the initiation location and the influence of the horizontal stress difference. Meanwhile, the fractures did not intersect with the wellbore when we traced back the fractures that propagated along or parallel to the face cleat. Specimens 1, 2, and EM-8 reported by Diamond and Oyler [44] showed the same result. Observations from specimens 1 and 2 showed that the fracture path was characterized as stairstep, and this was the result of the alternating propagation between the face cleat and the butt cleat. The report by Diamond and Oyler [44] also indicated that the strong heterogeneity and anisotropy in coal seams made hydraulic fractures propagate asymmetrically, and the fractures tended to extend to more friable and "soft" coal seams in the upper part of the Blue Creek Coalbed. The asymmetrical propagation of fractures was also found in specimen 4 . The comparison of fracture morphologies between the experiment and mineback observation verifies that the results of our experiments are reasonable and can explain phenomena observed in the field.

In the experiments, according to previous research results, $\sigma_{\mathrm{H}}$ and $\sigma_{\mathrm{h}}$ are inverted to simulate the change in the in situ stress field after the initial fracturing. However, in the actual formation, changes in the in situ stress field are very complex because of the influence of initial HFs and the long duration of CBM production. In addition, a $90^{\circ}$ inversion of stress is an extreme case; multiple field data show that the reorientation angle of a new $\mathrm{HF}$ is generally less than $90^{\circ}[50,51]$. The relationship between the horizontal stress changes and refracture reorientation cannot be derived systematically. The tests and analyses above have shown that changes in in situ stress indeed have significant effects on the propagation of refractures, especially on the breakdown pressure of refracturing, initiation orientation of refractures, and geometry of HFs. In order to improve the test plan and arrive at more general guiding rules, a more in-depth study should be carried out.

\section{Conclusions}

This paper validated a new measure for improving the productivity of fractured wells in coal seams. The effects of cleats and in situ stress inversion on new $\mathrm{HF}$ initiation and 
propagation in coal were studied through laboratory experiments. The following results were obtained:

(1) The type of the fracture curve reflects the propagation processes of the hydraulic fracture. The breakdown pressure needed to form new HFs is higher than that associated with initial fracturing, and $\mathrm{HF}$ reorientation occurs only when the net pressure exceeds the sum of the horizontal stress difference and the tensile strength of coal. Otherwise, fractures will continue to propagate along the initial HFs and weak planes

(2) Under low horizontal stress differences (0-2 MPa), cleats exert a significant influence on hydraulic fracture initiation. Although HFs propagate along cleats to increase connectivity and initial HFs are reopened during refracturing, it is difficult to form a new HF. The ability of cleats to control HF propagation diminishes as the horizontal stress difference increases

(3) Inversion of in situ stress promotes the creation of new HFs. Under high horizontal stress differences (more than $4 \mathrm{MPa}$ ), if the in situ stress does not change, only some branches are formed on the surface of the initial HFs. If the horizontal maximum and minimum stresses are inverted, new HFs will propagate perpendicular to the initial HFs

\section{Data Availability}

The data used to support the findings of this study are available from the corresponding author upon request.

\section{Conflicts of Interest}

The authors declare that there are no conflicts of interest regarding the publication of this paper.

\section{Acknowledgments}

This paper was supported the Major National Science and Technology Projects of China (No. 2017ZX05064003) and the Science Foundation of China University of Petroleum, Beijing (G1617B-B20C211).

\section{References}

[1] S. S. Askarimarnani and G. Willgoose, "Inferring the shape of fractures and hydraulic properties of the coal seam using inverse modeling on pumping test results-Broke, NSW, Australia," Procedia Environmental Sciences, vol. 25, no. 3, pp. 11-18, 2015.

[2] Z. Rui, Q. Han, H. Zhang, S. Wang, H. Pu, and K. Ling, "A new model to evaluate two leak points in a gas pipeline," Journal of Natural Gas Science and Engineering, vol. 46, pp. 491-497, 2016.

[3] Z. Rui, C. Li, F. Peng et al., "Development of industry performance metrics for offshore oil and gas project," Journal of Natural Gas Science \& Engineering, vol. 39, pp. 44-53, 2017.
[4] Z. Rui, J. Lu, Z. Zhang et al., "A quantitative oil and gas reservoir evaluation system for development," Journal of Natural Gas Science \& Engineering, vol. 42, pp. 31-39, 2017.

[5] Z. Rui, F. Peng, K. Ling, H. Chang, G. Chen, and X. Zhou, "Investigation into the performance of oil and gas projects," Journal of Natural Gas Science and Engineering, vol. 38, pp. 12-20, 2016.

[6] Z. Rui, X. Wang, Z. Zhang et al., "A realistic and integrated model for evaluating oil sands development with steam assisted gravity drainage technology in Canada," Applied Energy, vol. 213, pp. 76-91, 2018.

[7] T. Jacobs, "Renewing mature shale wells through refracturing," Journal of Petroleum Technology, vol. 66, no. 4, pp. 52-60, 2014.

[8] N. R. Warpinski, M. J. Mayerhofer, M. C. Vincent, C. L. Cipolla, and E. P. Lolon, "Stimulating unconventional reservoirs: maximizing network growth while optimizing fracture conductivity," Journal of Canadian Petroleum Technology, vol. 48, no. 10, pp. 39-51, 2009.

[9] X. Fu, Y. Qin, and B. Jiang, "Study on the "bottle-neck" problem of coalbed methane productivity of high-rank coal reservoirs," Geological Review, vol. 50, 2004.

[10] X. Su, X. Lin, S. Liu, M. Zhao, and Y. Song, "Geology of coalbed methane reservoirs in the southeast Qinshui Basin of China," International Journal of Coal Geology, vol. 62, no. 4, pp. 197210, 2005.

[11] T. A. Moore, "Coalbed methane: a review," International Journal of Coal Geology, vol. 101, no. 6, pp. 36-81, 2012.

[12] H. H. Abass, M. L. Van Domelen, and W. M. E. I. Rabaa, "Experimental observations of hydraulic fracture propagation through coal blocks," Systems Engineering, vol. 2, no. 2, pp. 108-128, 1990.

[13] H. H. Abass, S. Hedayati, and C. M. Kim, "Mathematical and experimental simulation of hydraulic fracturing in shallow goal seams," in SPE Eastern Regional Meeting, Lexington, KY, USA, October 1991.

[14] M. Khodaverdian, J. Mclennan, A. H. Jones, and R. A. Schraufnagel, "Influence of Near Wellbore Effects on Treatment Pressure in Coal," in Proceedings of the 1991 Coalbed Methane Symposium, The University Alabama/Tuscaloosa, Tuscaloosa, AL, USA, May 1991.

[15] G. S. Penny and M. W. Conway, "Coordinated Studies in Support of Hydraulic Fracturing of Coalbed Methane," in Society of Petroleum Engineers. SPE Annual Technical Conference and Exhibition, Dallas, TX, USA, October 1991.

[16] A. Dahi-Taleghani and J. E. Olson, "Numerical modeling of multistranded-hydraulic-fracture propagation: accounting for the interaction between induced and natural fractures," SPE Journal, vol. 16, no. 3, pp. 575-581, 2011.

[17] S. Huang, D. Liu, Y. Yao, Q. Gan, Y. Cai, and L. Xu, "Natural fractures initiation and fracture type prediction in coal reservoir under different in-situ stresses during hydraulic fracturing," Journal of Natural Gas Science \& Engineering, vol. 43, pp. 69-80, 2017.

[18] T. Wang, W. Hu, D. Elsworth et al., "The effect of natural fractures on hydraulic fracturing propagation in coal seams," Journal of Petroleum Science \& Engineering, vol. 150, pp. 180-190, 2017.

[19] Y. Li, Z. Rui, W. Zhao et al., "Study on the mechanism of rupture and propagation of T-type fractures in coal fracturing," 
Journal of Natural Gas Science and Engineering, vol. 52, pp. 379-389, 2018.

[20] N. R. Warpinski and L. W. Teufel, "Influence of geologic discontinuities on hydraulic fracture propagation (includes associated papers 17011 and 17074)," Journal of Petroleum Technology, vol. 39, no. 2, pp. 209-220, 1984.

[21] T. L. Blanton, "Propagation of hydraulically and dynamically induced fractures in naturally fractured reservoirs," in SPE Unconventional Gas Technology Symposium, Louisville, KY, USA, May 1986.

[22] G. Q. Zhang and M. Chen, "The relationship between the production rate and initiation location of new fractures in a refractured well," Petroleum Science and Technology, vol. 28, no. 7, pp. 655-666, 2010.

[23] S. C. Blair, R. K. Thorpe, and F. E. Heuze, "Laboratory Observations of the Effect of Geological Discontinuities on Hydrofracture Propagation," in American Rock Mechanics Association. The 30th U.S. Symposium on Rock Mechanics (USRMS), Morgantown, WV, USA, June 1989.

[24] N. R. Warpinski, J. C. Lorenz, P. T. Branagan, F. R. Myal, and B. L. Gall, "Examination of a cored hydraulic fracture in a deep gas well (includes associated papers 26302 and 26946)," SPE Production \& Facilities, vol. 8, no. 3, pp. 150-158, 1993.

[25] D. Q. Li, S. C. Zhang, and S. A. Zhang, "Experimental and numerical simulation study on fracturing through interlayer to coal seam," Journal of Natural Gas Science \& Engineering, vol. 21, pp. 386-396, 2014.

[26] M. A. Biot, "The theory of elasticity and consolidation for a porous anisothropic solid," Journal of Applied Physics, vol. 26, no. 2, pp. 182-185, 1955.

[27] J. L. Elbel and M. G. Mack, "Refracturing: observations and theories," in SPE Production Operations Symposium, Oklahoma City, OK, USA, March 1993.

[28] M. G. Mack and J. L. Elbel, "Hydraulic fracture orientation and pressure response during fracturing of producing wells," in 1st North American Rock Mechanics Symposium, Austin, TX, USA, June 1994.

[29] C. A. Wright, R. A. Conant, D. W. Stewart, and P. M. Byerly, "Reorientation of propped refracture treatments," in Rock Mechanics in Petroleum Engineering, Delft, Netherlands, August 1994.

[30] H. Liu, Z. Lan, G. Zhang, F. Hou, X. He, and X. Liu, "Evaluation of refracture reorientation in both laboratory and field scales," in SPE International Symposium and Exhibition on Formation Damage Control, Lafayette, LA, USA, February 2008.

[31] N. Roussel and M. Sharma, "Role of stress reorientation in the success of refracture treatments in tight gas sands," SPE Production \& Operations, vol. 27, no. 4, pp. 346-355, 2012.

[32] A. A. Daneshy, "Dynamic interaction within multiple limited entry fractures in horizontal wells: theory, implications, and field verification," in SPE Hydraulic Fracturing Technology Conference, The Woodlands, TX, USA, February 2015.

[33] Y. Zou, S. Zhang, Z. Tong, Z. Xiang, and G. Tiankui, "Experimental investigation into hydraulic fracture network propagation in gas shales using CT scanning technology," Rock Mechanics and Rock Engineering, vol. 49, no. 1, pp. 33-45, 2016.

[34] X. Ma, Y. Zou, N. Li, M. Chen, Y. Zhang, and Z. Liu, "Experimental study on the mechanism of hydraulic fracture growth in a glutenite reservoir," Journal of Structural Geology, vol. 97, pp. 37-47, 2017.

[35] C. J. de Pater, M. P. Cleary, T. S. Quinn, D. T. Barr, D. E. Johnson, and L. Weijers, "Experimental verification of dimensional analysis for hydraulic fracturing," SPE Production \& Facilities, vol. 9, no. 4, pp. 230-238, 1994.

[36] A. P. Bunger, R. G. Jeffrey, and E. Detournay, "Application of scaling laws to laboratory-scale hydraulic fractures," in Alaska Rocks 2005, The 40th U.S. Symposium on Rock Mechanics (USRMS), p. 9, Anchorage, AK, USA, June 2005.

[37] C. M. Kim and H. H. Abass, "Hydraulic fracture initiation from horizontal wellbores: laboratory experiments," Semiotica, vol. 2008, no. 168, pp. 45-65, 1991.

[38] T. Guo, S. Zhang, Z. Qu, T. Zhou, Y. Xiao, and J. Gao, "Experimental study of hydraulic fracturing for shale by stimulated reservoir volume," Fuel, vol. 128, no. 14, pp. 373-380, 2014.

[39] M. K. Fisher, J. R. Heinze, C. D. Harris, B. M. Davidson, C. A. Wright, and K. P. Dunn, "Optimizing horizontal completion techniques in the Barnett shale using microseismic fracture mapping," in SPE Annual Technical Conference and Exhibition, Houston, TX, USA, September 2004.

[40] A. A. Ketter, J. R. Heinze, J. L. Daniels, J. R. Heinze, and G. Waters, "A field study in optimizing completion strategies for fracture initiation in Barnett shale horizontal wells," SPE Production \& Operations, vol. 23, no. 3, pp. 373-378, 2008.

[41] D. Weng, L. Qun, X. Yun, L. Yang, L. Deqi, and W. Weixu, "Network fracturing techniques and its application in the field," Acta Petrolei Sinica, vol. 32, no. 2, pp. 280-284, 2011.

[42] B. Cai, Y. Ding, and Y. Lu, "Study and application of new infissure fracturing technique for improving stimulated reservoir volume," Petroleum Geology and Recovery Efficiency, vol. 19, no. 5, pp. 108-110, 2012.

[43] A. A. Daneshy, "Off-balance growth: a new concept in hydraulic fracturing," Journal of Petroleum Technology, vol. 55, no. 4, pp. 78-85, 2003.

[44] W. P. Diamond and D. C. Oyler, Effects of Stimulation Treatments on Coalbeds and Surrounding Strata. Evidence from Underground Observations, U.S. Department of the Interior Bureau of Mines Ri, Pittsburgh, PA, USA, 1987.

[45] C. E. Renshaw and D. D. Pollard, "An experimentally verified criterion for propagation across unbounded frictional interfaces in brittle, linear elastic materials," International Journal of Rock Mechanics and Mining Science \& Geomechanics Abstracts, vol. 32, no. 3, pp. 237-249, 1995.

[46] M. Sarmadivaleh and V. Rasouli, "Modified Reinshaw and Pollard criteria for a non-orthogonal cohesive natural interface intersected by an induced fracture," Rock Mechanics and Rock Engineering, vol. 47, no. 6, pp. 2107-2115, 2014.

[47] Z. Bennour, T. Ishida, Y. Nagaya et al., "Crack extension in hydraulic fracturing of shale cores using viscous oil, water, and liquid carbon dioxide," Rock Mechanics and Rock Engineering, vol. 48, no. 4, pp. 1463-1473, 2015.

[48] P. Li, "Theoretical study on reorientation mechanism of hydraulic fractures," Society of Petroleum Engineers, p. 7, 2008.

[49] I. D. Palmer, "Induced stresses due to propped hydraulic fracture in coalbed methane wells," in Low Permeability Reservoirs Symposium, p. 12, Denver, CO, USA, April 1993. 
[50] S. L. Wolhart, G. E. McIntosh, M. B. Zoll, and L. Weijers, "Surface tiltmeter mapping shows hydraulic fracture reorientation in the Codell Formation, Wattenberg Field, Colorado," in SPE Annual Technical Conference and Exhibition, p. 8, Anaheim, CA, USA, November 2007.

[51] S. Wang, G. Zhang, X. He, and X. He, "Case studies of propped refracture reorientation in the Daqing oil field," in SPE Hydraulic Fracturing Technology Conference, p. 7, College Station, TX, USA, January 2007. 

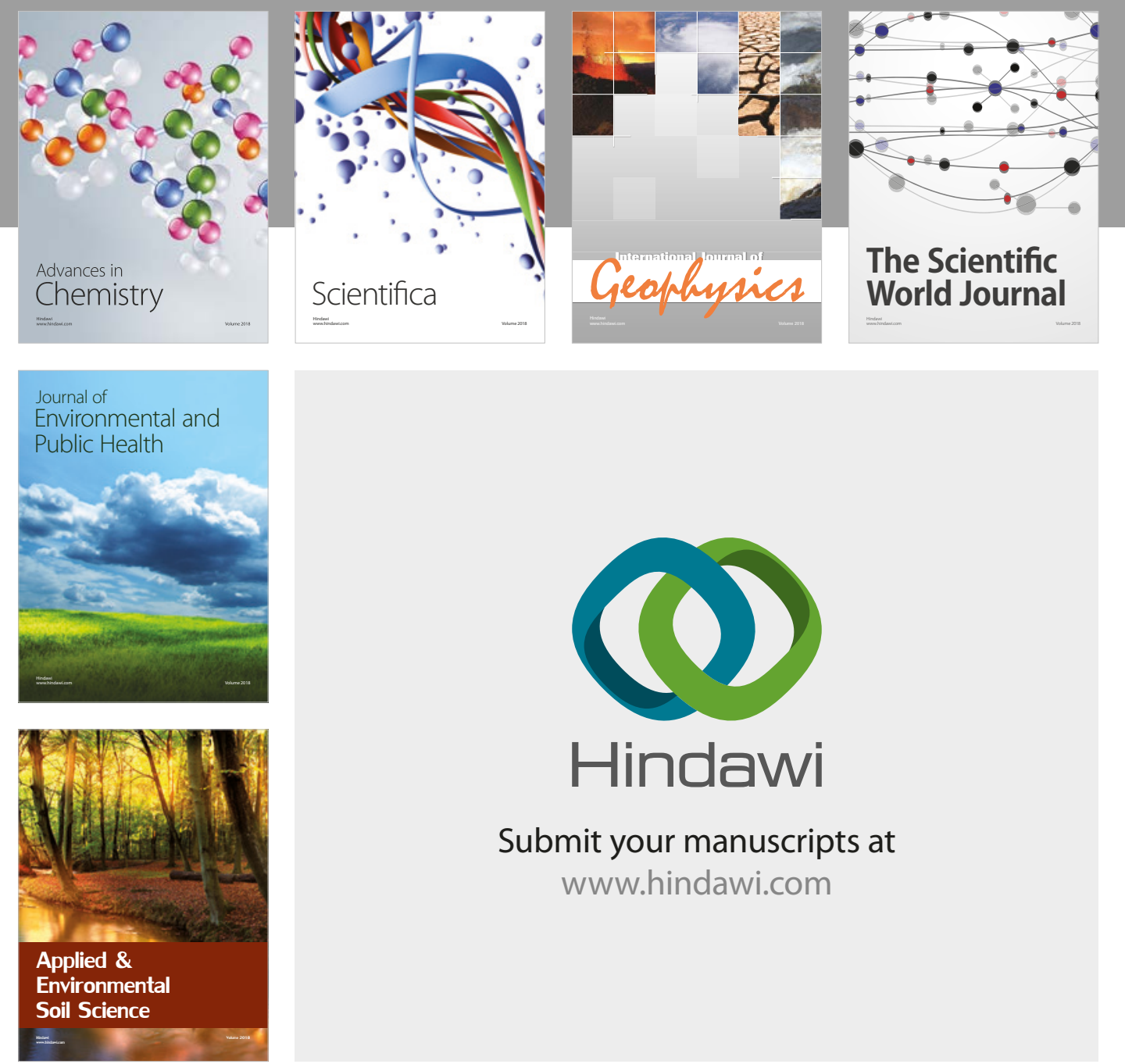

The Scientific

\section{World Journal}
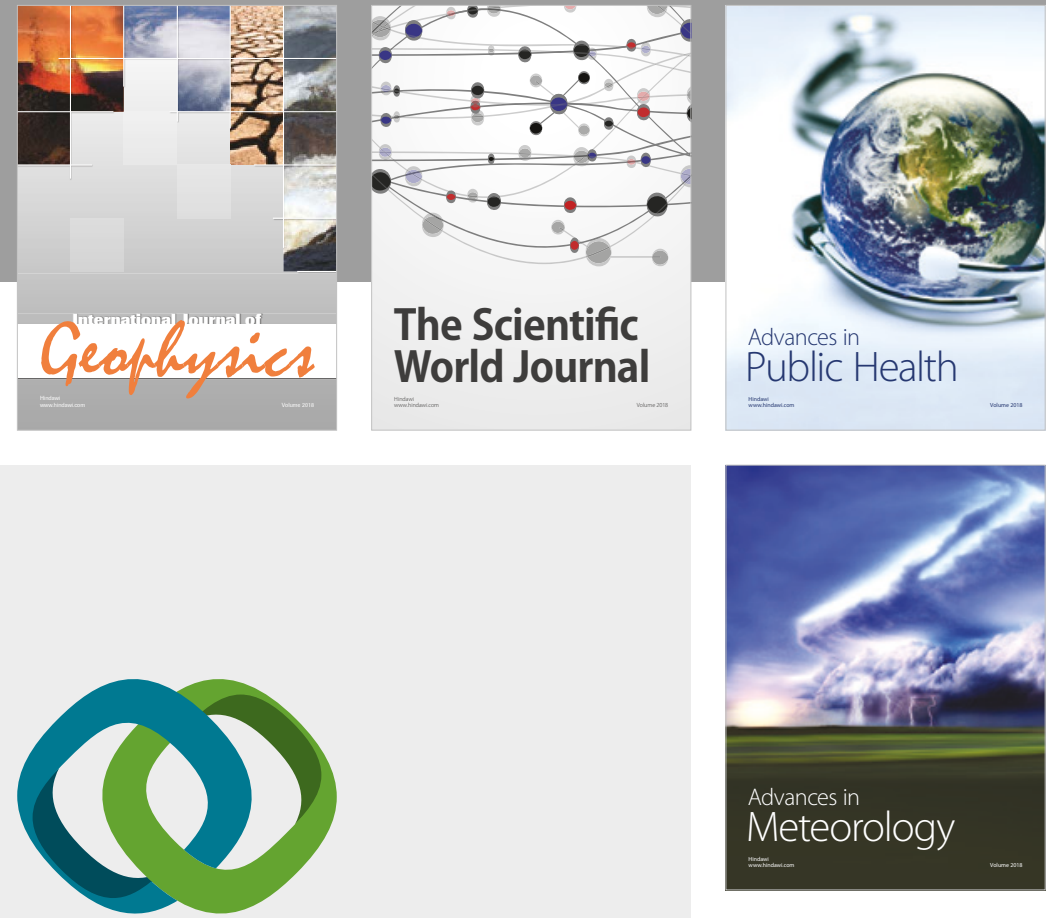

Advan

Public Health

\section{Hindawi}

Submit your manuscripts at

www.hindawi.com
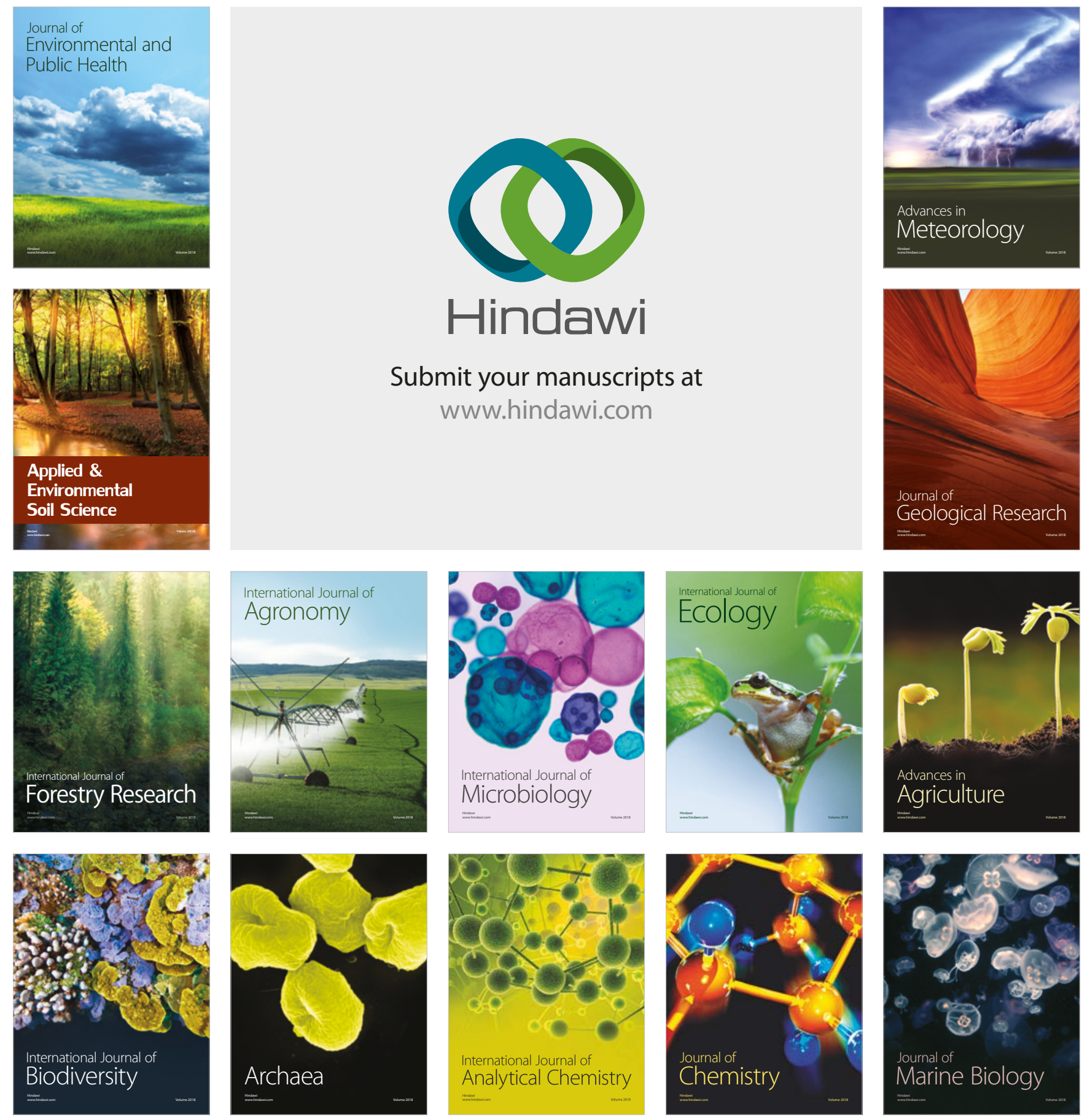